\title{
A global synthesis of seasonal temperature-size responses in copepods Seasonal temperature-size responses in copepods
}

\author{
Horne, Curtis R.; Hirst, Andrew G.; Atkinson, David; Neves, Aitana; Kiørboe, Thomas
}

Published in:

Global Ecology and Biogeography

Link to article, DOI:

$10.1111 / \mathrm{geb} .12460$

Publication date:

2016

Document Version

Peer reviewed version

Link back to DTU Orbit

Citation (APA):

Horne, C. R., Hirst, A. G., Atkinson, D., Neves, A., \& Kiørboe, T. (2016). A global synthesis of seasonal temperature-size responses in copepods: Seasonal temperature-size responses in copepods. Global Ecology and Biogeography, 25(8), 988-999. https://doi.org/10.1111/geb.12460

\section{General rights}

Copyright and moral rights for the publications made accessible in the public portal are retained by the authors and/or other copyright owners and it is a condition of accessing publications that users recognise and abide by the legal requirements associated with these rights.

- Users may download and print one copy of any publication from the public portal for the purpose of private study or research.

- You may not further distribute the material or use it for any profit-making activity or commercial gain

- You may freely distribute the URL identifying the publication in the public portal 


\section{A global synthesis of seasonal temperature-size responses in copepods}

Curtis R. Horne ${ }^{\text {a }}$ (c.horne@qmul.ac.uk)

Andrew. G. Hirst ${ }^{\mathrm{a}, \mathrm{b}}$ (a.g.hirst@qmul.ac.uk) Corresponding author

David Atkinson (davida@liverpool.ac.uk)

Aitana Neves ${ }^{\mathrm{b}}$ (aitana.neves@gmail.com)

Thomas Kiørboe ${ }^{\mathrm{b}}$ (tk@aqua.dtu.dk)

aSchool of Biological and Chemical Sciences, Queen Mary University of London, London, E1 4NS, United Kingdom.

${ }^{b}$ Centre for Ocean Life, National Institute for Aquatic Resources, Technical University of Denmark, Kavalergården 6, 2920, Charlottenlund, Denmark

${ }^{9}$ Institute of Integrative Biology, University of Liverpool, Liverpool, L69 7ZB, United Kingdom.

Key words: body size, temperature, chlorophyll, phenotypic plasticity, temporal, zooplankton

Running title: Seasonal temperature-size responses in copepods

Abstract: 300 | Main Text: 5349 | References: 65 | Figures: 5 | Tables: 1

\section{Statement of Authorship}

All authors designed the study and wrote the paper. $\mathrm{CH}$ collected the data and performed the meta-analysis. 


\section{$1 \quad$ ABSTRACT}

2 Aim

3 Body size is a master trait with significant ecological importance. Seasonal changes in body

4 size within diverse ectothermic species can result from different environmental conditions

5 experienced during ontogeny in subsequent generations. Whilst intra-specific changes in

6 adult size have been well studied under controlled experimental conditions and across

7 geographic ranges, comprehensive analyses of temporal changes are lacking, and there

8 remains considerable unexplained variation in body size responses within aquatic taxa.

9 Using planktonic copepods as an exemplar taxon, we quantify variation in adult body mass

10 within seasonally varying marine and freshwater environments. We describe how size

11 variation relates to temperature, food concentration (chlorophyll-a) and life history

12 characteristics, including feeding strategy.

13 Location

14 Global.

\section{Methods}

Using a meta-analytic approach, we extract quantitative data from published literature on seasonal size responses of copepods. We analyse competing models to determine the best predictors of these responses, and compare the relative importance of temperature and chlorophyll-a concentration in explaining body size variation.

\section{Results}

We quantify 140 seasonal size responses from 33 different global locations, representing 48 planktonic copepod species from 4 taxonomic orders. We find that temperature $\left(r^{2}=0.50\right)$, rather than food $\left(r^{2}=0.22\right)$, is the dominant explanatory variable of adult body size variation across seasons. A striking outcome is that current-feeding calanoids exhibit a 4-fold greater reduction in adult body mass per ${ }^{\circ} \mathrm{C}(-3.66 \%)$ compared to ambush feeding cyclopoids (- 
0.91\%). By contrast, species body size or reproductive strategy did not explain variation in

27 the seasonal temperature-size response.

\section{Main Conclusions}

Our findings lead us to suggest that feeding strategies may play a significant role in dictating the magnitude of seasonal temperature-size responses in copepods, with potential implications for other ectotherms with diverse feeding methods. Seasonal temperature-size responses were typically much more variable than responses in laboratory studies providing excess food, suggesting that field conditions modify the temperature-size response.

\section{INTRODUCTION}

Biologists have long been fascinated by body size variation (Bergmann, 1847; SchmidtNielsen, 1984), in part because this 'master trait' affects all vital rates, including feeding (Burns, 1968; Kiørboe, 2011), growth (Poston, 1990; Kiørboe \& Hirst, 2014), metabolism (Peters, 1983; Glazier, 2005; Hirst et al., 2014) and reproduction (Honĕk, 1993; Arendt, 2011), as well as many other aspects of the biology of an organism (Andersen et al., 2016). Consequently, identifying and understanding what drives variation in body size is of fundamental biological importance. Body size is sensitive to environmental conditions, due to the temperature dependence of physiological processes, as well as other effects such as changes in food availability. Ectothermic species that have short life-cycles and inhabit seasonal environments are typically subjected to varying environmental conditions across subsequent generations within a year. This is commonly linked to marked temporal shifts in adult body size over an annual cycle, as sequentially recruited adults are affected by different abiotic and biotic conditions over their ontogeny. Intra-specific variation in size related to seasonal variation in temperature has been found across a wide range of uni- and multicellular organisms, including bacteria (Chrzanowski et al., 1988), rotifers (Diéguez et al., 1998), copepods (Liang \& Uye, 1997; Hirst et al., 1999; Riccardi \& Mariotto, 2000; Dutz et 
al., 2012), cladocerans (Miyashita et al., 2011) and insects (Kari \& Huey, 2000), yet broadscale analyses of temporal changes in adult body size are lacking.

By contrast, intra-specific variation in size at stage has been well described in the laboratory under different conditions (Atkinson, 1994; Forster et al., 2012), and also spatially over latitude or across regions (Horne et al., 2015). The most frequently observed intra-specific response to warmer temperatures in ectotherms is a reduction in size-at-stage; this has been formalised as the Temperature-size Rule (TSR) (Atkinson, 1994). This phenotypically plastic response can be achieved within a single generation (Forster \& Hirst, 2012; Forster et al., 2013), and in many metazoans the proximate cause is attributed to differences in the temperature dependence of growth and development during ontogeny (van der Have \& de Jong, 1996; Forster et al., 2011a; Forster et al., 2011b; Zuo et al., 2012). The ultimate cause of this outcome however may be a complex of several factors (e.g. see Forster et al. 2012; Horne et al. 2015). Uncertainty still remains in the degree to which these responses are found in natural field conditions, where multiple variables can act simultaneously to influence body size. For instance, the relative contribution of food and temperature in determining seasonal shifts in adult size still needs to be resolved. Food availability impacts size at maturity, but while slower growth at lower temperature is frequently coupled with an increase in adult size, slower growth with reduced food availability is typically associated with smaller size at maturity (Berrigan \& Charnov, 1994). Further, food quality can dramatically alter the T-S response, even to the extent that the sign of the T-S response can be reversed under poor food quality (Diamond \& Kingsolver 2010). Identifying and understanding seasonal variation in body size will not only help to determine the ultimate causes of such variation, but will also aid in predicting future shifts associated with changes in climate (IPCC, 2014) and phenology (Visser \& Both, 2005). Our study aims to synthesise and quantify seasonal patterns in adult size of multivoltine species, going beyond previous species- and locationspecific studies, so that we might provide a broader understanding of such patterns. 
A recent meta-analysis of terrestrial and aquatic arthropods identified an impressive match between T-S responses measured under controlled laboratory conditions and intra-specific body size clines observed in the field across latitudes (Horne et al., 2015). The magnitude and direction of these responses revealed consistent differences in the strength and sign of the response between aquatic and terrestrial species. These results suggest that laboratory T-S responses and latitudinal body size clines may be driven by similar selective pressures within arthropods, specifically, by voltinism and season length trade-offs in terrestrial species (Kozłowski et al., 2004; Walters \& Hassall, 2006), and the need to balance oxygen demand and supply in larger aquatic species (Woods, 1999; Atkinson et al., 2006; Forster et al., 2012). However, in many small organisms, in which oxygen diffusion under normoxic conditions is likely to adequately meet metabolic demand, size reductions with warming are still very common; they are for example observed in bacteria, protists and small metazoans, such as copepods (Atkinson et al., 2003; Forster et al., 2012). Copepods are possibly the most numerous metazoan on the planet, are ecologically important, and play a pivotal role in marine and freshwater biogeochemistry and trophodynamics (Banse, 1995). Reduction in size with increasing temperature, consistent with the T-S rule (Atkinson, 1994), has been shown in many copepod species, both in controlled laboratory experiments (Horne et al., 2015), and across seasons in the field (Seasonal T-S responses) (Uye et al., 1983; Riccardi \& Mariotto, 2000; Hirst et al., 1999; Drif et al., 2010). Furthermore, the strength of the laboratory temperature-size response varies widely between species, to the extent that Horne et al. (2015) observed an approximate 30-fold difference between the strongest and weakest copepod T-S responses in their dataset on arthropods. It would appear, therefore, that another factor (or other factors) may be responsible for size reductions with warming observed in these smaller taxa, and identifying the likely causes is an important next step. Planktonic copepods are excellent model organisms in which to investigate seasonal size responses. Temporal changes in adult body size have commonly been examined in this 
taxon (Figure 1), especially in mid-latitude environments which demonstrate strong shifts in temperature and food, while most species have multiple generations within a year and short generation times of $>10$ to $<100$ days (Hirst \& Kiørboe, 2002). Thus, here we present and test a number of alternative hypotheses that may help to explain the considerable variation observed in body size sensitivity to warming in planktonic copepods.

Mature adult size is dependent in part upon obtaining sufficient food to meet maintenance and growth requirements, and size at maturity is controlled by different body size scaling of catabolism and anabolism (von Bertalanffy, 1957; Perrin, 1995):

$$
\frac{d M}{d t}=c_{s} \cdot M^{s}-c_{l} \cdot M^{l}
$$

where $s>0$ and $l>0$ are exponents for energy supply and loss respectively, and $c_{s}>0$ and $c_{l}>0$ represent the temperature dependence of the intercept terms in log-log scale. The point at which metabolic supply and demand intersect defines an organism's asymptotic mass $\left(\left.\frac{d M}{d t}\right|_{M_{A}}=0\right)$. In mathematical terms, the asymptotic mass, $M_{A}$, is given by

$$
c_{S} \cdot\left(M_{A}\right)^{s}=c_{l} \cdot\left(M_{A}\right)^{l} \Rightarrow \log \left(M_{A}\right)=\frac{\log \left(c_{s} / c_{l}\right)}{l-s}
$$

119 Temperature changes will affect both energy supply and expenditure, forcing the organism 120 into a new asymptotic mass. Hence, we can predict the induced relative change in 121 asymptotic mass per degree Celsius, noting that $f^{\prime}(x) / f(x)=f^{\prime}[\log (x)]$ :

$$
\frac{1}{M_{A}} \frac{d M_{A}}{d T}=\frac{d}{d T}\left[\log \left(M_{A}\right)\right]=\frac{1}{l-s} \cdot \frac{d}{d T}\left[\log \left(\frac{c_{S}}{c_{l}}\right)\right]
$$

122 Thus, the temperature dependence scales inversely with the difference in the mass scaling 123 of supply and demand (I-s), and is also influenced by the temperature dependence of the 
intercepts. Moreover, within this framework, the strength of the T-S cline should be independent of body mass.

Despite overwhelming evidence in favour of the TSR in a diverse range of ectotherms, there remains considerable unexplained variation in the strength of the response between species and taxonomic groups, which are most likely attributed to key differences in life history traits and their associated metabolic constraints. In copepods and many other small zooplankton, food acquisition is governed by prey availability and uptake. Species within the order Calanoida largely utilise feeding currents to entrain and capture prey (Kiørboe, 2011), with a few exceptions; by contrast, species within the non-Calanoida orders, i.e., the Harpacticoida, Cyclopoida and Poecilostomatoida, lack an ability to produce a feeding current and are either ambush feeders (Cyclopoida; Paffenhöfer 1993), or they feed on surfaces, which in the planktonic environment is provided by marine snow aggregates (Harpacticoida; Koski et al. 2005), or they are parasitic (e.g. many Poecilostomatoida; Huys \& Boxshall 1991). There is evidence that feeding mode is an important correlate of metabolic rates (respiration), clearance, growth and ingestion rates (Kiørboe \& Hirst, 2014). Ignoring parasitic copepods, the body mass dependence of clearance rate differs between feeding current feeders and more passive ambush and surface feeders (Kiørboe, 2011), suggesting a possible difference in the temperature-body size sensitivity between different feeding behaviours. We cannot yet predict the magnitude and direction of the T-S response since we do not know how metabolic rates change with mass during ontogeny, and we also do not know how the intercept terms vary with temperature. However, these considerations lead us to suggest that some of the variability in T-S responses may be due to differences in feeding behaviour.

Another potential influence on the T-S response is reproductive strategy. In copepods, reproductive strategy can be divided into broadcast spawning and sac spawning. Sac 
spawners carry eggs in external sacs, and have much lower fecundity rates than broadcast spawners (Hirst \& Kiørboe, 2002). Sac spawners commonly do not lay the next batch of eggs until the previous batch has hatched from the attached sac(s) (Ward \& Hirst, 2007), hence egg production is limited by the egg hatch time (Hirst \& Bunker, 2003). By contrast, broadcasters have much higher fecundity rates, and are less likely to be limited by clutch size or egg hatch rates in the same way. The potentially different thermal sensitivities of egg development versus egg production rates may produce different solutions for size at maturity (and in turn its temperature dependence) between these two reproductive strategies. However, even in the absence of clear evidence of such a difference in thermal sensitivity of egg production and hatching, optimum size may change to different degrees if the cost of carrying versus not carrying egg sacs is temperature dependent. For example, feeding rates of ectotherms, including predators such as fish, typically increase with warming (Barneche et al., 2008), and such increased risk of mortality to prey organisms may amplify any small differences in size- and fecundity- related trade-offs observed between broadcast and sac spawners at cooler temperatures. In principle, therefore, differences in the optimum body size response to temperature between the two spawning strategies can be hypothesized.

Our study therefore aims to: 1. Quantify and synthesise for the first time the seasonal temperature-size responses of a wide range of planktonic copepod species, and to compare these with responses under controlled laboratory conditions. 2. Examine the temperature dependence of size at maturity in copepods, based around major differences between taxonomic orders, species body sizes, modes of feeding (feeding current vs. active ambush feeding), and reproductive strategy. 3. Assess the relative importance of food concentration and temperature in driving seasonal size change.

\section{METHODS}


176 We searched the literature for studies in which the adult body size of planktonic copepods

177 was assessed on multiple occasions during an annual cycle. In addition to temperature we

178 also recorded the concentration of phytoplankton pigment chlorophyll-a (Chl-a) when this was reported. Chl-a concentration is commonly used as a proxy for phytoplankton biomass and food availability; indeed, adult fecundity and juvenile growth in many copepods correlates to this term (Hirst \& Bunker, 2003; Bunker \& Hirst, 2004). To reduce potential sampling bias in the sizes of animals collected, only those studies in which the adults were sampled across the entire depth of the water column, or across most of the depth range of the species, were included. Adult size data were collected as either lengths or dry, wet, or carbon mass. These measurements were subsequently converted to dry mass (mg) using published intra-specific regressions. If these were not available, regressions for closely related species, or more general inter-specific regressions, were used. A list of the data sources is found in Appendix 1. All raw data and conversions are detailed in Data S1 in Supporting Information. Taxonomic order and family were confirmed for each species using the World Registry of Marine Species (WoRMS Editorial Board, 2015).

In order to test which equation form best describes the relationship between mass and temperature within a species, we used AIC (Akaike Information Criterion) to compare linear, quadratic, exponential and allometric fits to the data. We found that the exponential equation form was overwhelmingly favoured for modelling seasonal T-S responses, as judged by Akaike weights (see Table S1 in Supporting Information for full details). We therefore used slopes of the natural log $(\operatorname{In})$ of dry mass vs. temperature were determined for all individuals and transformed into percentage change in dry mass per degree Celsius, using the formula $\left(\exp ^{(\text {slope })}-1\right)^{*} 100=\%$ change in mass per ${ }^{\circ} \mathrm{C}$ (Forster et al., 2012). This value represents the seasonal temperature-size response, with a negative value showing a reduction in body 
mass with increasing temperature, and hence following the same trend as the TemperatureSize Rule. Size responses from multiple studies of the same species were then combined into a simple mean to generate a single species-specific seasonal T-S value, separated by sex.

To quantify relationships between body mass and Chl-a, the species-specific slopes of the natural log (In) of dry mass vs. Chl-a concentration ( $\mu \mathrm{g}$ per litre) were determined for all individuals and transformed into percentage change in dry mass per $\mu \mathrm{g}^{-1}$, again using the formula $\left(\exp ^{(\text {slope })}-1\right)^{*} 100=\%$ change in mass per $\mu g \cdot L^{-1}$, to generate a chlorophyll-size $(C$ S) response. The mean $95 \%$ confidence intervals of T-S and C-S responses, calculated from the $95 \%$ confidence intervals of the individual estimated slopes, are presented for each order in Table S2 of our Supporting Information. For all datasets in which we had both a measure of temperature and Chl-a concentration $(n=80)$, we compared the coefficient of determination $\left(R^{2}\right)$ of both parameters (i.e. by comparing the $R^{2}$ of each seasonal T-S response with its corresponding C-S response), to determine whether one consistently explained significantly more of the variation in seasonal body size clines than the other. Given that temperature is a mechanistic driver of variation in primary productivity, we also utilised an alternate approach to examine these relationships; first we regressed body mass against temperature and then subsequently regressed the residuals from this on Chl-a concentration, to determine how much of the seasonal variation in body size could be attributed to $\mathrm{Chl}-\mathrm{a}$ after accounting for temperature.

All statistical analyses were conducted using the free statistical software package $R$ (R Core Team, 2014). We derived several candidate models to determine the best predictors of seasonal T-S responses based on the Akaike's information criterion (AIC). In order to determine whether species body size impacts the T-S response, we included $\log _{10}$ species 
mass at a reference temperature $\left(15^{\circ} \mathrm{C}\right)$ as a predictor, as such an allometric relationship has previously been shown to be significant (Forster et al., 2012; Horne et al., 2015). Taxonomic order, $\log _{10}$ body mass (at $15^{\circ} \mathrm{C}$ calculated using species and sex-specific slopes) and sex were incorporated as fixed variables in a global linear mixed effects model (using package Ime4), with species nested within family, and latitude included as random effects on the intercept. When selecting our random effects, we considered the estimates of variance explained by each of our proposed random variables (environment type (marine vs. freshwater), latitude, and species nested within family) and used stepwise elimination of nonsignificant terms to determine which parameters to include in the final model. All possible combinations of the global model terms were compared using the dredge function in the MuMln package in $R$. The best model was identified as that with lowest small-samples corrected AIC (AICc), and Akaike weights $\left(w_{i}\right)$ were used to determine the probability $(0-1)$ of each candidate model being the best fit model (i.e. if $w_{i}=0.9$, there is a $90 \%$ probability that a given model is the best fit model among those considered and given the data available). Where the difference between a model's AICc and the lowest AICc (i.e. $\triangle \mathrm{AICc}$ ) is $<2$, a set of best fit models, rather than a single best model, can be assumed, and model averaging may be used to identify the best predictor variables across the top candidate models and determine their relative importance (computed for each variable as the sum of the Akaike weights from all models in which they appear). In addition to AIC, a series of $F$ tests (using the 'anova' function in $R$ ) were used to verify the significance $(p<0.05)$ of each parameter's effect on the strength of the seasonal T-S response. Post hoc comparisons were made using a Tukey HSD test.

To compare seasonal T-S responses with laboratory T-S responses, we used the extensive T-S response dataset of Horne et al. (2015), supplementing this where possible with newly identified data following identical methods for acquiring data. 


\section{RESULTS}

257

We derived a total of 140 seasonal T-S responses from 33 different global locations (Fig. 1), within the latitudinal range of $25^{\circ}$ to $61^{\circ}$, hence largely falling around mid-latitudes (with a dominance of northern hemisphere locations). This in part reflects well-studied temperate environments with strong seasonality, while also being inhabited by copepod species with multiple generations in a year. The data set included 48 planktonic copepod species from 4 taxonomic orders (Calanoida, Cyclopoida, Harpacticoida, Poecilostomatoida). These species-specific seasonal T-S responses had negative slopes in $87 \%$ of cases, with a mean reduction in size of $-2.87 \pm 0.65 \%(95 \% \mathrm{Cl})$ body mass per ${ }^{\circ} \mathrm{C}$ (Fig. 2), reinforcing the generality of the negative T-S response in copepods. The overall strength or direction of the seasonal T-S response did not vary significantly across latitudes $\left(F_{1,138}=1.20, p=0.27\right)$. Of the 80 seasonal body size clines for which we had a measure of Chl-a concentration (corresponding to 33 species), across all orders we observe a mean body mass response of $0.98 \pm 2.01 \%(95 \% \mathrm{Cl})$ per $\mu \mathrm{gL}^{-1}$, which does not differ significantly from zero $\left(t_{79}=0.97\right.$, $p=0.34$ ) (Fig. 2). On average, across all taxonomic orders temperature explained more of the variation in seasonal body mass than Chl-a concentration: this is inferred from the mean $R^{2}$ values of each parameter when both were modelled separately $(0.44 \pm 0.07$ vs. $0.22 \pm 0.05$ respectively $(95 \% \mathrm{Cl}))$, and also when comparing body mass-temperature regressions with regressions of the resulting residuals against Chl-a concentration $(0.44 \pm 0.07$ vs. $0.07 \pm 0.03$ respectively $(95 \% \mathrm{Cl})$ ) (see Fig. S1 in Supporting Information). Considering each of the four orders separately, temperature always explained more of the variation in adult body mass than did Chl-a concentration.

In explaining variation in the strength of the seasonal T-S response among planktonic copepods, the model with the lowest AICc includes only taxonomic order as a fixed variable, 
whilst all other candidate models have a $\Delta \mathrm{AICc}>2$ (Table 1). Thus, given the data available, we may reject the other candidate models in favour of a single best fit model in which taxonomic order has a significant independent effect on the strength of the seasonal T-S response $\left(F_{3,82}=9.43, \mathrm{p}<0.001\right)$. Post hoc comparisons (Tukey HSD) show that Calanoida $\left(n=66\right.$, mean $=-3.66 \pm 0.70 \%$ body mass ${ }^{\circ} \mathrm{C}^{-1} ; 95 \% \mathrm{Cl}$ ) have a significantly stronger negative seasonal T-S response than both Cyclopoida $\left(n=12\right.$, mean $=-0.91 \pm 0.59 \%$ body mass ${ }^{\circ} \mathrm{C}^{-1}$; $95 \% \mathrm{Cl}$ ) and Poecilostomatoida $\left(n=6\right.$, mean $=1.36 \pm 3.06 \%$ body mass $\left.{ }^{\circ} \mathrm{C}^{-1} ; 95 \% \mathrm{Cl}\right)$, but not Harpacticoida $\left(n=2\right.$, mean $=-1.19 \pm 3.60 \%$ body mass $\left.{ }^{\circ} \mathrm{C}^{-1} ; 95 \% \mathrm{Cl}\right)$, though our seasonal data for this order are sparse, including only male and female Euterpina acutifrons. We note specifically the different temperature response between the calanoids, which use feedingcurrents, and ambush feeding cyclopoid copepods, with a 4-fold difference in the strength of the seasonal T-S response observed between these two groups (Fig. 3). We find no significant change in the strength of the response with mean species body mass in either the Calanoida $\left(F_{1,101}=0.11, \mathrm{p}=0.75\right)$ or non-Calanoida orders $\left(F_{1,35}=2.75, \mathrm{p}=0.11\right)$, supporting our prediction that any change in mature body size is independent of mean species body mass in these smaller taxa (Fig. 4).

Reproductive strategy also varies within and between orders; calanoid species can be either broadcast or sac spawners, but are more commonly the former ( $n=44$ vs. $n=22$ for broadcast and sac spawners respectively in our dataset), whilst all species in the three remaining orders considered here are sac spawners. Given that taxonomic order and reproductive strategy correlate exactly in 3 of the 4 orders in our dataset, while in calanoids both reproductive strategies occur, we tested for differences in the seasonal T-S response between broadcasters and sac spawners exclusively in calanoids, finding no significant effect $\left(F_{1,64}=0.71, \mathrm{p}=0.40\right)$. Equally, we tested for order-level differences in the seasonal T-S response exclusively in sac spawners (i.e. by excluding any broadcast spawning calanoid species), and find significant differences in the strength of the seasonal T-S response 
between taxonomic orders, still observing a 4-fold significant difference between calanoids and cyclopoids ( $t$-test; $t=-4.51, \mathrm{df}=31, \mathrm{p}<0.0001$ ). This leads us to suggest that reproductive strategy is not responsible for driving the observed differences in seasonal T-S responses between taxonomic orders and, hence, explains why we chose to exclude the latter from our global linear mixed effects model.

Despite the numerous other variables that may act to obscure the correlation between body mass and seasonal temperature, we find a strong match between the mean Calanoida seasonal T-S response $(-3.66 \pm 0.70 \%)$ and mean T-S response $(-3.20 \pm 0.49 \%)$ measured in the laboratory under conditions of excess food ( $t$-test; $t=-1.09, \mathrm{df}=79, \mathrm{p}=0.28)$. However, we note that the two datasets comprise different species. Indeed, when we regress speciesspecific seasonal T-S responses against laboratory T-S responses for the small number of species for which we have both sets of data $(n=12)$, separating responses by sex, we observe much greater variation in seasonal T-S responses than those measured under controlled laboratory conditions (Fig. 5). This suggests that food quantity/quality, and potentially other environmental variables, are impacting the T-S response in the field. There appears to be no systematic difference in the strength of laboratory and seasonal T-S responses between the sexes, such that sex has no significant effect on the strength of the seasonal T-S response, either across species $\left(F_{1,84}=0.03, \mathrm{p}=0.86\right)$ or intra-specifically (paired $t$-test; $t=1.35, \mathrm{df}=37, \mathrm{p}=0.19)$. Unfortunately we are unable to make further meaningful comparisons between field and laboratory responses. For example, we could not compare the broad differences between taxonomic orders we observe in the seasonal T-S data with laboratory data, as very few laboratory studies on species other than calanoids have been conducted; our dataset contains male and female laboratory T-S responses for just 2 planktonic cyclopoid species and a single harpacticoid species. 
335 Our work combines field data from numerous studies worldwide (Fig. 1), going beyond controlled laboratory-based T-S studies to demonstrate broad patterns in the thermal size responses of marine and freshwater planktonic copepods. Despite numerous other variables that may act to complicate the T-S signal in the field, we show that almost $90 \%$ of copepod species in our dataset follow the Temperature-Size Rule (TSR) in seasonal environments, maturing at a smaller adult body mass in warmer conditions. Yet, as we may expect, seasonal T-S responses appear much more variable compared to those measured under controlled conditions in the laboratory (Fig. 5), suggesting that other environmental factors, in addition to temperature, may play a role in driving seasonal body size variation in the field. We should also consider that the temperature at which adults are collected is unlikely to change little, and yet temperatures may vary considerably.

Food availability has also been shown to have a direct influence on body size (Berrigan \& Charnov, 1994; Diamond \& Kingsolver, 2010), though we find that Chl-a concentration explains very little of the seasonal variation in body mass, when both modelled independently and after accounting for the effects of temperature. This suggests that temperature is much more significant in driving body size responses in these natural populations. Higher food quantity typically leads to larger size at maturity in ectotherms, and we observe a positive but non-significant percentage change in adult body mass with increasing Chl-a concentration on average (Fig. 2). Chl-a concentration commonly correlates significantly with juvenile growth and adult fecundity rates in many natural populations of planktonic copepods (Hirst \& Bunker, 2003; Bunker \& Hirst, 2004), and hence is generally 
considered a reasonable proxy of food availability. However, many copepods have an

omnivorous diet that does not exclusively include prey containing this pigment (e.g. including heterotrophic ciliates and flagellates (Calbet \& Saiz, 2005)), and the proxy also fails to account for variation in prey quality (Pond et al., 1996), which has been shown to alter the temperature-size response, even reversing its sign at times (Diamond \& Kingsolver, 2010). Here we find little evidence for sign reversal when comparing laboratory and field animals. Time lags might also obscure the correlation between Chl-a concentration and body size. As food availability commonly varies over a much shorter timescale than generation time, whilst temperature varies over a relatively longer timescale, correlations with the latter are likely to be much more reliable. Although greater chlorophyll concentration is often associated with increased growth (Hirst \& Bunker, 2003; Bunker \& Hirst, 2004), consumer abundance is also predicted to increase with primary productivity (O'Connor et al., 2009). Our analysis does not account for the abundance of the copepods, and hence we are unable to assess the role of food availability on a per capita basis. Assuming metabolic rate has a $Q_{10}$ of 2.5 and scales with body mass ${ }^{0.75}$ (Zuo et al., 2012), a simple calculation suggests that an organism would have to decrease its body mass by approximately $11.5 \%$ per ${ }^{\circ} \mathrm{C}$ of warming to offset the increase in metabolic rate associated with this temperature increase. Given that calanoid copepods on average reduce their body mass by only $3.66 \%{ }^{\circ} \mathrm{C}^{-1}$, this compensates for approximately a third of the increase in metabolic rate per ${ }^{\circ} \mathrm{C}$ of warming. If resources were limiting and kept constant then population abundance would have to fall substantially with warming to accommodate the extra metabolic demand, even with reduced body size of individuals.

Beyond variation in temperature and food availability, we might expect predation by ectotherms to increase with warming in the field (Kordas et al., 2011). This in turn may lead to increased copepod mortality, selecting for earlier maturation and resulting in a reduced adult body size. Copepods can also detect and perceive chemical signals released by 
predators, such as fish kairomones, the presence of which has been shown to trigger faster development and earlier maturation at a smaller body size in calanoids (Gutiérrez et al., 2010). Thus, increased predation risk in the warm and associated increases in mortality and the presence of chemical cues may amplify the temperature-size response in the field.

The relative strength of the seasonal T-S response does not vary significantly between the sexes in this study, evidence of which can also be observed in Figure 5. These findings agree with the broader analysis across Arthropoda, for which T-S responses were found to not significantly differ between the sexes (Hirst et al., 2015). Rensch's rule suggests that male body size varies more than female body size, irrespective of which is the larger sex (Rensch, 1960). Applied within species, the rule would predict an increase in sexual size dimorphism (SSD) with increasing body size in species where males are the larger sex, and a decrease in SSD with body size in species where females are larger. Thus males should consistently have the greater size variation, yet we find no evidence to support this pattern at the intra-specific level. Our finding at the intra-specific level here concurs with there being isometry between male and female size seen across copepod species (Hirst \& Kiørboe 2014), and suggests that the selection pressures on the seasonal T-S response have been equally as strong for both males and females.

Though recent studies have begun to identify broad trends in both the magnitude and direction of the T-S response, for example between terrestrial and aquatic species (Forster et al., 2012; Horne et al., 2015), there remains a large amount of variation in the strength of the response that is yet to be explained. This is especially true for planktonic species which are only a few millimetres in size or less, where oxygen availability in most conditions appears unlikely to be a driver. Indeed, our most compelling finding is the significant difference in the strength of seasonal T-S responses between species of calanoid and 
cyclopoid (Fig. 3), both of which typically employ different feeding modes. We find that calanoids exhibit much greater size plasticity upon temperature changes than non-calanoids. This is consistent with the hypothesis that feeding mode may influence the T-S response, since all calanoids can produce a feeding current to harvest prey, while none of the other orders do so. The extent to which the T-S response differs between these two feeding modes depends on the differences in both size-scaling and thermal response of feeding in relation to metabolism. Thus, in order to thoroughly test this hypothesis, one would need estimates of within-species mass scaling and temperature dependence of feeding and metabolism. While some estimates of between-species body mass scaling of respiration and feeding of the two groups exist (e.g., Kiørboe \& Hirst 2014), the body mass-dependent changes in vital rates during ontogeny are typically different (Hirst et al., 2014; Glazier et al., 2015), and thus needed for these groups. A further complication arises from the fact that feeding mode may change during ontogeny: while all cyclopoids are ambush feeders throughout their development, many calanoids are ambush feeders during the nauplii stage, and feeding current feeders during the copepodite stages; or they may switch between feeding modes in the copepodite stages (Kiørboe, 2011).

We note the association between taxonomic order and feeding mode in our dataset, and appreciate the potential difficulty in disentangling effects of feeding strategy from other orderspecific differences in physiology and behaviour. For example, all cyclopoids in our dataset are sac spawners, whilst calanoid species can be either broadcast or sac spawners, but are more commonly the former. However, we find no substantial effect of reproductive strategy on the sensitivity of mature body mass to temperature. Whilst broadcast and sac spawning planktonic copepods have markedly different rates of adult fecundity (Bunker \& Hirst, 2004), egg mass production rates (Hirst \& Bunker, 2003) and egg mortality (Hirst \& Kiørboe, 2002), they appear to have somewhat similar rates of juvenile growth, development and mortality (Hirst \& Kiørboe, 2002; Hirst \& Bunker, 2003). The T-S responses of species with 
440 determinate growth are largely generated during the juvenile phase of ontogeny (Forster \&

441 Hirst, 2012). Similarity of important life history rates during the juvenile phase may therefore

442 explain the lack of difference in the T-S responses within the calanoids based upon 443 reproductive strategy. Expanding our analysis in future to consider ambush feeding calanoid copepods, such as in the genera Tortanus and Pareuchaeta, will help to more definitively separate effects of feeding strategy from order-level differences. Unfortunately at present, suitable data are not available on these taxa. We recommend that future experimental studies comparing species-specific size variation in response to temperature, both within and between taxonomic orders, should focus on those taxonomic groups that are currently data deficient.

Given that body size is an important predictor of fitness, and warming is a prominent feature of climate change, there is an urgent need to accurately predict changes in body size with temperature. This is particularly the case in zooplankton which globally represent a primary resource for invertebrates and vertebrates, including fish (Ware \& Thomson, 2005). Changes in body size will not only affect individual and population fitness, but may impact feeding rates and alter food web connectivity given the size dependency of trophic processes (Hansen et al., 1994; Rice et al., 2015), as planktonic food webs are especially highly sizestructured (Webb, 2012). Measuring and accounting for abundance in the field would also help to define the relationship between food availability per capita and adult body size under natural conditions. This may be particularly informative in light of the fact that the temperature-size response in the majority of ectotherms appears to compensate for only a small proportion of the predicted increase in metabolic rate with temperature, whilst metabolic rate in autotrophs (and thus primary productivity) increases substantially less with warming than metabolic rate in heterotrophs (Allen et al., 2005). 
467 We wish to thank the many authors who kindly donated their data or clarified aspects of their studies. $\mathrm{CRH}$ is supported by a Natural Environment Research Council Studentship NE/L501797/1. AGH was supported by the Natural Environment Research Council and

470 Department for Environment, Food and Rural Affairs [grant number NE/L003279/1, Marine

471 Ecosystems Research Programme]. The Centre for Ocean Life is a VKR Centre of 472 Excellence supported by the Villum Foundation. We thank the reviewers, their comments helped to greatly improve the paper.

\section{SUPPORTING INFORMATION}

Data S1 Seasonal body size data used in this study

Table S1 AIC output comparing linear, quadratic, exponential and allometric fits for determining seasonal temperature-size responses.

Table S2 Mean 95\% confidence intervals of individual T-S and C-S regressions for each taxonomic order.

Figure S1 Comparison of species-specific coefficients of determination for temperature and Chl-a concentration in explaining seasonal body mass changes, values averaged by order.

\section{BIOSKETCH}

The work presented here results from an ongoing collaboration between researchers from Queen Mary University of London, the University of Liverpool and the Centre for Ocean Life, Technical University of Denmark. We use a range of approaches such as meta-analysis, experimentation, conceptualisation and modelling to establish and test governing rules of ecology and evolution. A major focus is the ecology, physiology and population processes of marine species, especially plankton, including the impact of a changing climate. Further 491 information, including details of our latest research and publications, can be found at our research group website: $\underline{w w w . a q u a t i c-e c o l o g y . c o . u k}$ 
494

495

496

497

498

499

500

501

502

503

504

505

506

507

508

509

510

511

512

513

514

515

516

517

Allen, A. P., Gillooly, J. F. \& Brown, J. H. (2005) Linking the global carbon cycle to individual metabolism. Functional Ecology, 19, 202-213.

Andersen, K., Berge, T., Gonçalves, R., Hartvig, M., Heuschele, J., Hylander, S., Jacobsen, N., Lindemann, C., Martens, E., Neuheimer, A., Olsson, K., Palacz, A., Prowe, F., Sainmont, J., Traving, S., Visser, A., Wadhwa, N. \& Kiørboe, T. (2016) Characteristic sizes of life in the oceans, from bacteria to whales. Annual Review of Marine Science, 8, 3.1-3.25.

Arendt, J. D. (2011) Size-fecundity relationships, growth trajectories, and the temperaturesize rule for ectotherms. Evolution, 65, 43-51.

Atkinson, D. (1994) Temperature and organism size - A biological law for ectotherms. Advances in Ecological Research, 25, 1-58.

Atkinson, D., Ciotti, B. J. \& Montagnes, D. J. S. (2003) Protists decrease in size linearly with temperature: ca. $2.5 \%$ degrees $\mathrm{C}^{-1}$. Proceedings of the Royal Society of London B Biological Sciences, 270, 2605-2611.

Atkinson, D., Morley, S. A. \& Hughes, R. N. (2006) From cells to colonies: at what levels of body organization does the 'temperature-size rule' apply? Evolution \& Development, 8, 202-214.

Banse, K. (1995) Zooplankton: Pivotal role in the control of ocean production: I. Biomass and production. ICES Journal of Marine Science: Journal du Conseil, 52, 265-277.

Barneche, D. R., Floeter, S. R., Ceccarelli, D. M., Frensel, D. M. B., Dinslaken, D. F., Mário, H. F. S. \& Ferreira, C. E. L. (2008) Feeding macroecology of territorial damselfishes (Perciformes: Pomacentridae). Marine biology, 156, 289-299.

Bergmann, C. (1847) Über die verhältnisse der wärmeökonomie der thiere zu ihrer grösse. Göttinger Studien, Göttingen, 3, 595-708.

Berrigan, D. \& Charnov, E. L. (1994) Reaction norms for age and size at maturity in response to temperature - A puzzle for life historians. Oikos, 70, 474-478. 
521 Bunker, A. J. \& Hirst, A. G. (2004) Fecundity of marine planktonic copepods: global rates and patterns in relation to chlorophyll a, temperature and body weight. Marine Ecology-Progress Series, 279, 161-181.

Burns, C. W. (1968) The relationship between body size of filter-feeding Cladocera and the maximum size of particle ingested. Limnology and Oceanography, 13, 675-678.

Calbet, A. \& Saiz, E. (2005) The ciliate-copepod link in marine ecosystems. Aquatic Microbial Ecology, 38, 157-167.

Chrzanowski, T. H., Crotty, R. D. \& Hubbard, G. J. (1988) Seasonal variation in cell volume of epilimnetic bacteria. Microbial Ecology, 16, 155-163.

Diamond, S. E. \& Kingsolver, J. G. (2010) Environmental dependence of thermal reaction norms: host plant quality can reverse the temperature size rule. American Naturalist, 175, 1-10.

Diéguez, M., Modenutti, B. \& Queimaliños, C. (1998) Influence of abiotic and biotic factors on morphological variation of Keratella cochlearis (Gosse) in a small Andean lake. Hydrobiologia, 387, 289-294.

Dutz, J., van Beusekom, J. E. E. \& Hinrichs, R. (2012) Seasonal dynamics of fecundity and recruitment of Temora longicornis in the Baltic Sea. Marine Ecology Progress Series, 462, 51-66.

Forster, J. \& Hirst, A. G. (2012) The Temperature-size Rule emerges from ontogenetic differences between growth and development rates. Functional Ecology, 26, 483492.

Forster, J., Hirst, A. G. \& Atkinson, D. (2011a) How do organisms change size with changing temperature? The importance of reproductive method and ontogenetic timing. Functional Ecology, 25, 1024-1031.

Forster, J., Hirst, A. G. \& Atkinson, D. (2012) Warming-induced reductions in body size are greater in aquatic than terrestrial species. Proceedings of the National Academy of Sciences of the United States of America, 109, 19310-19314. 
Forster, J., Hirst, A. G. \& Esteban, G. F. (2013) Achieving temperature-size changes in a unicellular organism. The ISME journal, 7, 28-36.

Forster, J., Hirst, A. G. \& Woodward, G. (2011b) Growth and development rates have different thermal responses. American Naturalist, 178, 668-678.

Glazier, D. S. (2005) Beyond the '3/4-power law': variation in the intra- and interspecific scaling of metabolic rate in animals. Biological reviews, 80, 611-662.

Glazier, D. S., Hirst, A. G. \& Atkinson, D. (2015) Shape shifting predicts ontogenetic changes in metabolic scaling in diverse aquatic invertebrates. Proceedings of the Royal Society of London B: Biological Sciences, 282, 20142302.

Gutiérrez, M. F., Paggi, J. C. \& Gagneten, A. M. (2010) Fish kairomones alter life cycle and growth of a calanoid copepod. Journal of Plankton Research, 32, 47-55.

Hansen, B., Bjornsen, P. K. \& Hansen, P. J. (1994) The size ratio between planktonic predators and their prey. Limnology and Oceanography, 39, 395-403.

Hirst, A. G. \& Bunker, A. J. (2003) Growth of marine planktonic copepods: Global rates and patterns in relation to chlorophyll a, temperature, and body weight. Limnology and Oceanography, 48, 1988-2010.

Hirst, A. G., Glazier, D. S. \& Atkinson, D. (2014) Body shape shifting during growth permits tests that distinguish between competing geometric theories of metabolic scaling. Ecology Letters, 17, 1274-1281.

Hirst, A. G., Horne, C. R. \& Atkinson, D. (2015) Equal temperature-size responses of the sexes are widespread in arthropod species. Proceedings of the Royal Society B: Biological Sciences, 282, 20152475.

Hirst, A. G. \& Kiørboe, T. (2002) Mortality of marine planktonic copepods: global rates and patterns. Marine Ecology-Progress Series, 230, 195-209.

Hirst, A. G. \& Kiørboe, T. (2014) Macroevolutionary patterns of sexual size dimorphism in copepods. Proceedings of the Royal Society B: Biological Sciences, 281. 
574 Hirst, A. G., Sheader, M. \& Williams, J. A. (1999) Annual pattern of calanoid copepod abundance, prosome length and minor role in pelagic carbon flux in the Solent, UK. Marine Ecology Progress Series, 177, 133-146.

Honĕk, A. (1993) Intraspecific variation in body size and fecundity in insects: A general relationship. Oikos, 66, 483-492.

Horne, C. R., Hirst, A. G. \& Atkinson, D. (2015) Temperature-size responses match latitudinal-size clines in arthropods, revealing critical differences between aquatic and terrestrial species. Ecology Letters, 18, 327-335.

Huys, R. \& Boxshall, G. A. (1991) Copepod evolution, edn. Ray Society, London.

IPCC. (2014) Climate change 2013 - The physical science basis, edn. Cambridge University Press, Cambridge.

Kari, J. S. \& Huey, R. B. (2000) Size and seasonal temperature in free-ranging Drosophila subobscura. Journal of Thermal Biology, 25, 267-272.

Kiørboe, T. (2011) How zooplankton feed: mechanisms, traits and trade-offs. Biological reviews, 86, 311-339.

Kiørboe, T. \& Hirst, A. G. (2014) Shifts in mass scaling of respiration, feeding, and growth rates across life-form transitions in marine pelagic organisms. The American naturalist, 183, E118-E130.

Kordas, R. L., Harley, C. D. G. \& O'Connor, M. I. (2011) Community ecology in a warming world: the influence of temperature on interspecific interactions in marine systems. Journal of Experimental Marine Biology and Ecology, 400, 218-226.

Koski, M., Kiørboe, T. \& Takahashi, K. (2005) Benthic life in the pelagic: aggregate encounter and degradation rates by pelagic harpacticoid copepods. Limnology and Oceanography, 50, 1254-1263.

Kozłowski, J., Czarnoleski, M. \& Danko, M. (2004) Can optimal resource allocation models explain why ectotherms grow larger in cold? Integrative and Comparative Biology, 44, 480-493. 
601 Liang, D. \& Uye, S. (1997) Seasonal reproductive biology of the egg-carrying calanoid copepod Pseudodiaptomus marinus in a eutrophic inlet of the Inland Sea of Japan. Marine biology, 128, 409-414.

Miyashita, L. K., Gaeta, S. A. \& Lopes, R. M. (2011) Life cycle and reproductive traits of 605 marine podonids (Cladocera, Onychopoda) in a coastal subtropical area. Journal of Plankton Research, 33, 779-792.

Paffenhöfer, G.-A. (1993) On the ecology of marine cyclopoid copepods (Crustacea,

O'Connor, M. I., Piehler, M. F., Leech, D. M., Anton, A. \& Bruno, J. F. (2009) Warming and resource availability shift food web structure and metabolism. PLoS Biology, 7, e1000178. Copepoda). Journal of Plankton Research, 15, 37-55.

Perrin, N. (1995) About Berrigan and Charnov's life-history puzzle. Oikos, 73, 137-139.

Peters, R. H. (1983) The ecological implications of body size, edn. Cambridge University Press, Cambridge.

Pond, D., Harris, R., Head, R. \& Harbour, D. (1996) Environmental and nutritional factors determining seasonal variability in the fecundity and egg viability of Calanus helgolandicus in coastal waters off Plymouth, UK. Marine Ecology Progress Series, $143,45-63$.

Poston, H. A. (1990) Effect of body size on growth, survival, and chemical composition of Atlantic salmon fed soy lecithin and choline. The Progressive Fish-Culturist, 52, 226230.

R Core Team. (2014) R: A language and environment for statistical computing., edn. R Foundation for Statistical Computing, Vienna, Austria.

Rensch, B. (1960) Evolution above the species level, edn. Columbia University Press, New York, NY.

Riccardi, N. \& Mariotto, L. (2000) Seasonal variations in copepod body length: A comparison between different species in the lagoon of Venice. Aquatic Ecology, 34, 243-252. 
628 Rice, E., Dam, H. \& Stewart, G. (2015) Impact of climate change on estuarine zooplankton: surface water warming in Long Island Sound is associated with changes in copepod size and community structure. Estuaries and Coasts, 38, 13-23.

Schmidt-Nielsen, K. (1984) Scaling: why is animal size so important?, edn. Cambridge University Press, Cambridge.

van der Have, T. M. \& de Jong, G. (1996) Adult size in ectotherms: Temperature effects on growth and differentiation. Journal of Theoretical Biology, 183, 329-340.

Visser, M. E. \& Both, C. (2005) Shifts in phenology due to global climate change: the need for a yardstick. Proceedings of the Royal Society B-Biological Sciences, 272, 25612569.

von Bertalanffy, L. (1957) Quantitative laws in metabolism and growth. The Quarterly Review of Biology, 32, 217-231.

Walters, R. J. \& Hassall, M. (2006) The temperature-size rule in ectotherms: May a general explanation exist after all? The American naturalist, 167, 510-523.

Ward, P. \& Hirst, A. G. (2007) Oithona similis in a high latitude ecosystem: abundance, distribution and temperature limitation of fecundity rates in a sac spawning copepod. Marine biology, 151, 1099-1110.

Ware, D. M. \& Thomson, R. E. (2005) Bottom-up ecosystem trophic dynamics determine fish production in the Northeast Pacific. Science, 308, 1280-1284.

Webb, T. J. (2012) Marine and terrestrial ecology: unifying concepts, revealing differences. Trends in Ecology \& Evolution, 27, 535-541.

Woods, H. A. (1999) Egg-mass size and cell size: Effects of temperature on oxygen distribution. American Zoologist, 39, 244-252.

WoRMS Editorial Board. (2015) World Register of Marine Species. Available from http://www.marinespecies.org at VLIZ. Accessed 2015-10-22.

Zuo, W., Moses, M. E., West, G. B., Hou, C. \& Brown, J. H. (2012) A general model for effects of temperature on ectotherm ontogenetic growth and development. Proceedings of the Royal Society B: Biological Sciences, 279, 1840-1846. 


\section{APPENDIX 1 - Data Sources}

658

Ara, K. (2001a) Length-weight relationships and chemical content of the planktonic copepods in the Cananéia Lagoon estuarine system, Sao Paulo, Brazil. Plankton Biology and Ecology, 48, 121-127.

Ara, K. (2001b) Temporal variability and production of Euterpina acutifrons (Copepoda: Harpacticoida) in the Cananéia Lagoon estuarine system, Sao Paulo, Brazil. Hydrobiologia, 453, 177-187.

Ara, K. (2002) Temporal variability and production of Temora turbinata (Copepoda: Calanoida) in the Cananéia Lagoon estuarine system, São Paulo, Brazil. Scientia Marina, 66, 399-406.

Arima, D., Yamaguchi, A., Abe, Y., Matsuno, K., Saito, R., Asami, H., Shimada, H. \& Imai, I. (2014) Seasonal changes in body size and oil sac volume of three planktonic copepods, Paracalanus parvus (Claus, 1863), Pseudocalanus newmani Frost, 1989 and Oithona similis Claus, 1866, in a temperate embayment: what controls their seasonality? Crustaceana, 87, 364-375.

Belmonte, G. \& Cavallo, A. (1997) Body size and its variability in the copepod Acartia margalefi (Calanoida) from Lake Acquatina (SE Italy). Italian Journal of Zoology, $\mathbf{6 4}$ $377-382$.

Beyrend-Dur, D., Souissi, S. \& Hwang, J.-S. Population dynamics of calanoid copepods in the subtropical mesohaline Danshuei Estuary (Taiwan) and typhoon effects. Ecological Research, 28, 771-780.

Bottrell, H. H. \& Robins, D. B. (1984) Seasonal variations in length, dry weight, carbon and nitrogen of Calanus helgolandicus from the Celtic Sea. Marine Ecology Progress Series, 14, 259-268. 
Bozkurt, A. \& Can, M. F. (2014) Seasonal variations in body length and fecundity of 2 copepod species: Thermocyclops crassus (Fischer, 1853) and Eudiaptomus drieschi (Poppe \& MrÃ $i z e k, 1895)$. Turkish Journal of Zoology, 38, 222-228.

Christou, E. D. \& Verriopoulos, G. C. (1993) Length, weight and condition factor of Acartia clausi (Copepoda) in the Eastern Mediterranean. Journal of the Marine Biological Association of the United Kingdom, 73, 343-353.

Crawford, P. \& Daborn, G. R. (1986) Seasonal variations in body size and fecundity in a copepod of turbid estuaries. Estuaries, 9, 133-141.

Devreker, D., Souissi, S. \& Seuront, L. (2005) Effects of chlorophyll concentration and temperature variation on the reproduction and survival of Temora longicornis (Copepoda, Calanoida) in the Eastern English Channel. Journal of Experimental Marine Biology and Ecology, 318, 145-162.

Drif, K., Hirst, A. G. \& Hay, S. (2010) Seasonal abundance and egg production rates of Oithona similis and Pseudocalanus elongatus in the northern North Sea: a first comparison of egg-ratio and incubation methods. Marine Ecology Progress Series, 415, $159-175$.

Dutz, J., van Beusekom, J. E. E. \& Hinrichs, R. (2012) Seasonal dynamics of fecundity and recruitment of Temora longicornis in the Baltic Sea. Marine Ecology Progress Series, 462, 51-66.

El-Maghraby, A. M. (1965) The seasonal variations in length of some marine planktonic copepods from the eastern Mediterranean at Alexandria. Crustaceana, 8, 37-47.

Gaudy, R. \& Verriopoulos, G. (2004) Spatial and seasonal variations in size, body volume and body proportion (prosome: urosome ratio) of the copepod Acartia tonsa in a semi-closed ecosystem (Berre lagoon, western Mediterranean). Hydrobiologia, 513, 219-231.

Hada, A., Uye, S. \& Onbe, T. (1986) The seasonal life cycle of Sinocalanus tenellus (Copepoda: Calanoida) in a brackish-water pond. Bulletin of Plankton Society of Japan, 33, 29-41. 
Hirst, A. G., Sheader, M. \& Williams, J. A. (1999) Annual pattern of calanoid copepod abundance, prosome length and minor role in pelagic carbon flux in the Solent, UK. Marine Ecology Progress Series, 177, 133-146.

Huang, C., Uye, S. \& Onbe, T. (1993) Geographic distribution, seasonal life cycle, biomass and production of a planktonic copepod Calanus sinicus in the Inland Sea of Japan and its neighboring Pacific Ocean. Journal of Plankton Research, 15, 1229-1246.

Liang, D. \& Uye, S. (1996a) Population dynamics and production of the planktonic copepods in a eutrophic inlet of the Inland Sea of Japan .2. Acartia omorii. Marine biology, 125, $109-117$.

Liang, D. \& Uye, S. (1996b) Population dynamics and production of the planktonic copepods in a eutrophic inlet of the Inland Sea of Japan .3. Paracalanus sp. Marine biology, 127, 219-227.

Liang, D. \& Uye, S. (1997) Population dynamics and production of the planktonic copepods in a eutrophic inlet of the Inland Sea of Japan .4. Pseudodiaptomus marinus, the egg-carrying calanoid. Marine biology, 128, 415-421.

Liang, D., Uye, S. \& Onbe, T. (1994) Production and Loss of Eggs in the Calanoid Copepod Centropages abdominalis Sato in Fukuyama Harbor, the Inland Sea of Japan. Bulletin of Plankton Society of Japan, 41, 131-142.

Liang, D., Uye, S. \& Onbe, T. (1996) Population dynamics and production of the planktonic copepods in a eutrophic inlet of the Inland Sea of Japan .1. Centropages abdominalis. Marine biology, 124, 527-536.

Marshall, S. M. (1949) On the biology of the small copepods in Loch Striven. Journal of the Marine Biological Association of the United Kingdom, 28, 45-113.

Peters, J., Dutz, J. \& Hagen, W. (2013) Trophodynamics and life-cycle strategies of the copepods Temora longicornis and Acartia longiremis in the Central Baltic Sea. Journal of Plankton Research, 35, 595-609. 
Reed, E. B. \& Aronson, J. G. (1989) Seasonal variation in length of copepodids and adults of Diacyclops thomasi (Forbes) in two Colorado montane reservoirs (Copepoda). Journal of Crustacean Biology, 67-76.

Riccardi, N. \& Mariotto, L. (2000) Seasonal variations in copepod body length: A comparison between different species in the lagoon of Venice. Aquatic Ecology, 34, 243-252.

Smith, S. L. \& Lane, P. V. Z. (1987) On the life history of Centropages typicus: responses to a fall diatom bloom in the New York Bight. Marine biology, 95, 305-313.

Sun, X., Liang, Z., Zou, J. \& Wang, L. (2013) Seasonal variation in community structure and body length of dominant copepods around artificial reefs in Xiaoshi Island, China. Chinese Journal of Oceanology and Limnology, 31, 282-289.

Sun, X., Sun, S., Li, C. \& Wang, M. (2012) Seasonal change in body length of important small copepods and relationship with environmental factors in Jiaozhou Bay, China. Chinese Journal of Oceanology and Limnology, 30, 404-409.

Tellioglu, A. (2006) Seasonal variations in copepod body length: a comparison between different species in Keban Dam Lake, Turkey. Crustaceana, 79, 11-22.

Temperoni, B., Viñas, M. D., Diovisalvi, N. \& Negri, R. (2011) Seasonal production of Oithona nana Giesbrecht, 1893 (Copepoda: Cyclopoida) in temperate coastal waters off Argentina. Journal of Plankton Research, 33, 729-740.

Uye, S. (1982) Population Dynamics and Production of Acartia clausi Giesbrecht (Copepoda:Calanoida) in Inlet Waters. Journal of Experimental Marine Biology and Ecology, 57, 55-83.

Uye, S., Iwai, Y. \& Kasahara, S. (1982) Reproductive biology of Pseudodiaptomus marinus (Copepoda: Calanoida) in the Inland Sea of Japan. Bulletin of Plankton Society of Japan. Bulletin of Plankton Society of Japan, 29, 25-35.

Uye, S. \& Shibuno, N. (1992) Reproductive biology of the planktonic copepod Paracalanus $s p$. in the Inland Sea of Japan. Journal of Plankton Research, 14, 343-358. 
774

775

776

777

778

779

780

781

782

783

784

785

786

787

788

789

Uye, S. I. \& Sano, K. (1998) Seasonal variations in biomass, growth rate and production rate of the small cyclopoid copepod Oithona davisae in a temperate eutrophic inlet. Marine Ecology Progress Series, 163, 37-44.

Viitasalo, M., Koski, M., Pellikka, K. \& Johansson, S. (1995) Seasonal and long-term variations in the body size of planktonic copepods in the northern Baltic Sea. Marine biology, 123, 241-250.

Warren, G. J., Evans, M. S., Jude, D. J. \& Ayers, J. C. (1986) Seasonal variations in copepod size: effects of temperature, food abundance, and vertebrate predation. Journal of Plankton Research, 8, 841-853.

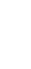

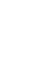

\section{4}

5

6

(1)


790 Table 1. AIC output comparing the relative strength of candidate models in explaining 791 variation in seasonal T-S responses. The best model, shown in bold, is identified as that with 792 the lowest small-samples corrected AIC (AICc). Given that the difference between the lowest $793 \mathrm{AICc}$ and those of the alternative models (i.e. $\Delta \mathrm{AICc}$ ) is $>2$, we may favour a single best fit 794 model in which taxonomic order has a significant independent effect on the strength of the

795

796

797

798

799

800

801

802

803

804

805

806

807

808

809

810

811 seasonal T-S response. An 'intercept only' model, shown in italics, is included for comparison. Akaike weight $\left(w_{i}\right)$ denotes the probability of a given model being the best fit model in the candidate set. The number of parameters $(K)$ in each model is shown. Mass is the species adult body mass at $15^{\circ} \mathrm{C}$.

\begin{tabular}{lccccc} 
Model & $\mathrm{K}$ & Log-likelihood & AICc & $\Delta$ AICc & $w_{i}$ \\
\hline Intercept & 5 & -328.40 & 667.25 & 5.08 & 0.04 \\
Order & $\mathbf{8}$ & $\mathbf{- 3 2 2 . 5 3}$ & $\mathbf{6 6 2 . 1 6}$ & $\mathbf{0 . 0 0}$ & $\mathbf{0 . 5 2}$ \\
Order+Sex & 9 & -322.51 & 664.40 & 2.24 & 0.17 \\
Log $_{10}$ Mass+Order & 9 & -322.53 & 664.44 & 2.27 & 0.17 \\
Log $_{10}$ Mass+Order+Sex & 10 & -322.51 & 666.72 & 4.55 & 0.05 \\
Log $_{10}$ Mass & 6 & -327.89 & 668.41 & 6.25 & 0.02 \\
Sex & 6 & -328.38 & 669.40 & 7.24 & 0.01 \\
Log $_{10}$ Mass+Sex & 7 & -327.77 & 670.38 & 8.22 & 0.01 \\
\hline
\end{tabular}

(1)


813 Fig.1. World map indicating the location of studies $(n=33)$ from which copepod seasonal size 814 responses were recorded. Studies from freshwater environments are indicated by the light grey circles whilst marine environments are indicated by the dark grey circles.

817 Fig. 2. Species-specific $\%$ change in body mass $( \pm 95 \% \mathrm{Cl})$ for seasonal T-S $\left(\right.$ per $\left.{ }^{\circ} \mathrm{C}\right)$ and $\mathrm{C}$ $818 \mathrm{~S}\left(\right.$ per $\left.\mu \mathrm{g} . \mathrm{L}^{-1}\right)$ responses, averaged by order. Solid grey lines shows the mean seasonal T-S and $\mathrm{C}-\mathrm{S}$ response across all orders with $95 \% \mathrm{Cl}$ indicated by the shaded area.

Fig. 3. (A) Seasonal temperature-size responses of adult copepods for individual species, including both males and females, categorized by order (Calanoida, Cyclopoida, Harpacticoida, Poecilostomatoida) and family (Acartidae (Ac), Calaniidae (Ca), Centropagidae (Ce), Clausocalanidae (Cl), Diaptomidae (Di), Paracalanidae (Pa), Pseudodiaptomidae (Ps), Temoridae (Te), Cyclopidae (Cy), Oithonidae (Oi), Euterpinidae $(E)$, Corycaeidae $(C)$, Oncaeidae (On)). Where more than one study has been undertaken on a species, the mean (and $\pm \mathrm{SE}$ ) are plotted. Dashed horizontal lines indicate the mean seasonal T-S response for the Calanoida and Cyclopoida orders. Dashed vertical lines divide taxonomic families. Species names preceded by an asterisk are sac spawners, whilst all other species are broadcast spawners. (B) Species-specific seasonal T-S responses $\left(\begin{array}{l} \pm 95 \% \mathrm{Cl}\end{array}\right)$, averaged by order. Different letters above data points indicate significant differences, whilst shared letters indicate no significant difference. Note the significant difference between feeding-current feeding Calanoida and ambush feeding Cyclopoida. $\log _{10}$ adult dry mass $(\mathrm{mg})$, categorized by taxonomic order. We find no significant 
837 relationship between the strength of seasonal T-S responses and species body mass across 838 either Calanoida $\left(F_{1,101}=0.11, \mathrm{p}=0.75\right.$; solid line $)$ or non-Calanoida species $\left(F_{1,35}=2.75\right.$, $839 p=0.11$; dashed line). Data for both females and males are included where possible. 840 "NS"=not significant.

842 Fig. 5. Male (M) and female (F) species-specific laboratory temperature-size (T-S) 843 responses versus seasonal T-S responses in planktonic copepods. Seasonal T-S responses 844 are much more variable than laboratory T-S responses and there is a significant positive 845 correlation (RMA regression; $R^{2}=0.25$ ) between the two. Dashed grey line indicates $y=x$ for 846 comparison. There appears to be no significant difference in the strength of seasonal and 847 laboratory T-S responses between the sexes. 


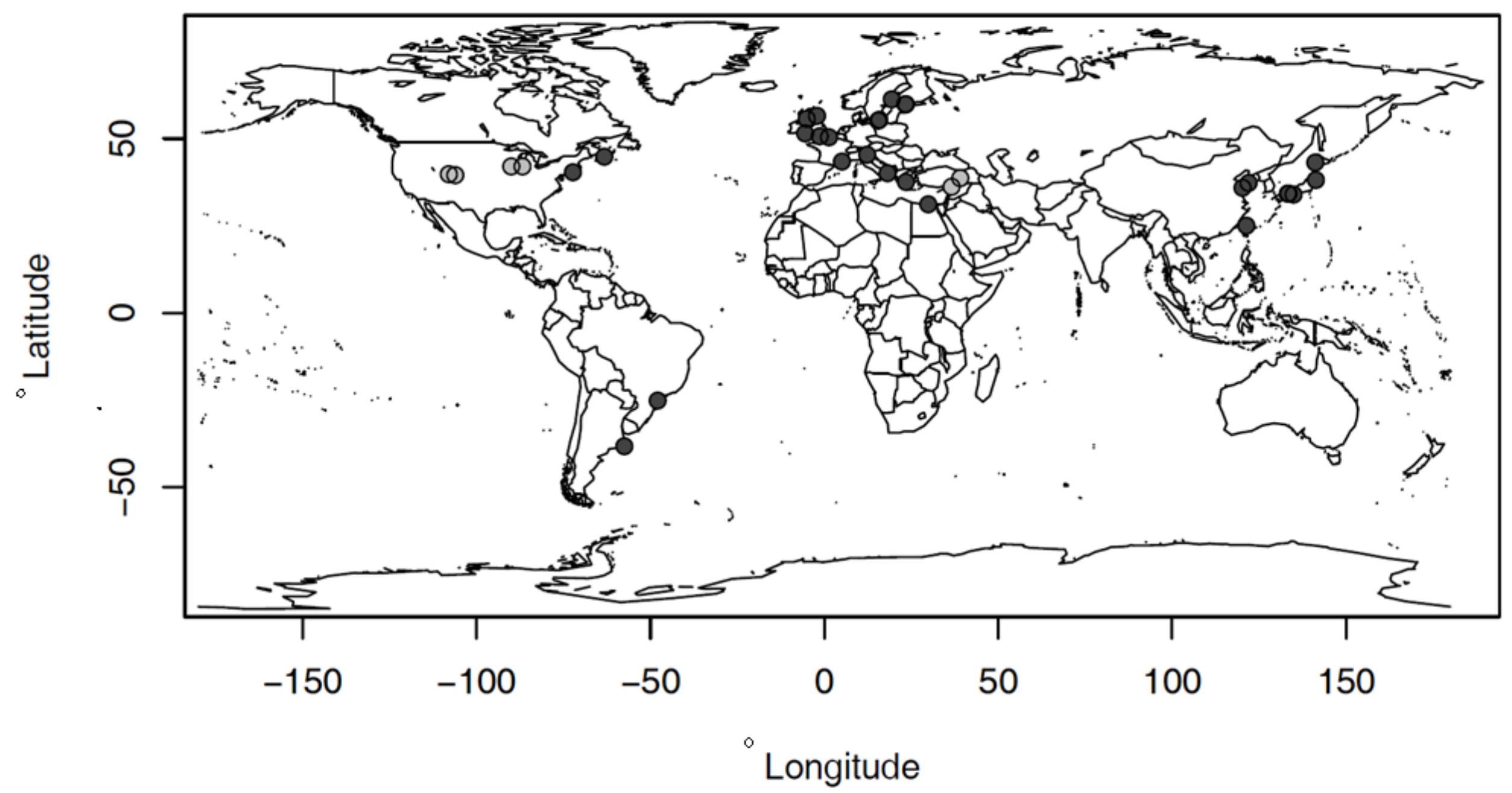

Figure 1 


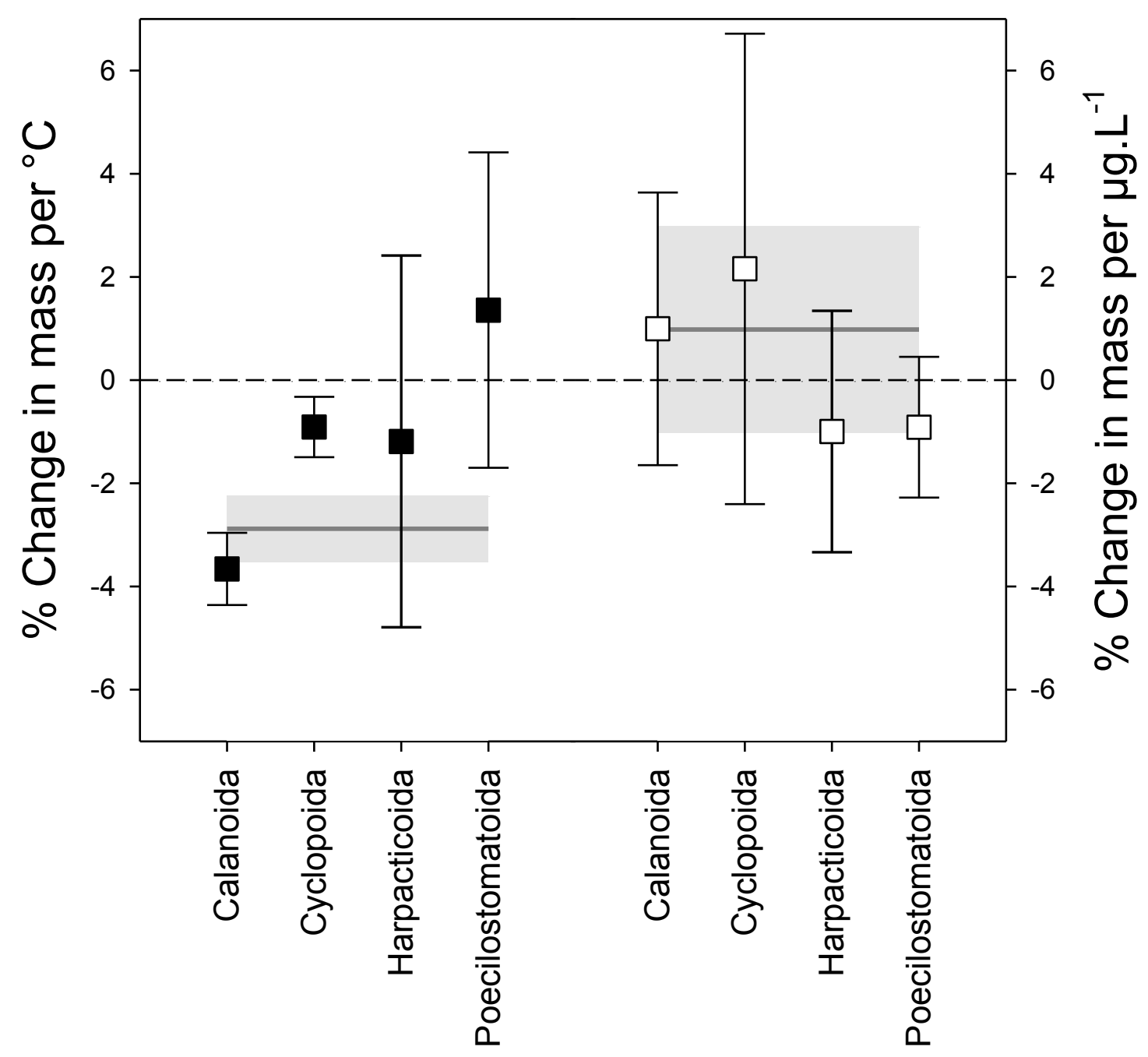

Temperature

Chlorophyll a

Figure 2 


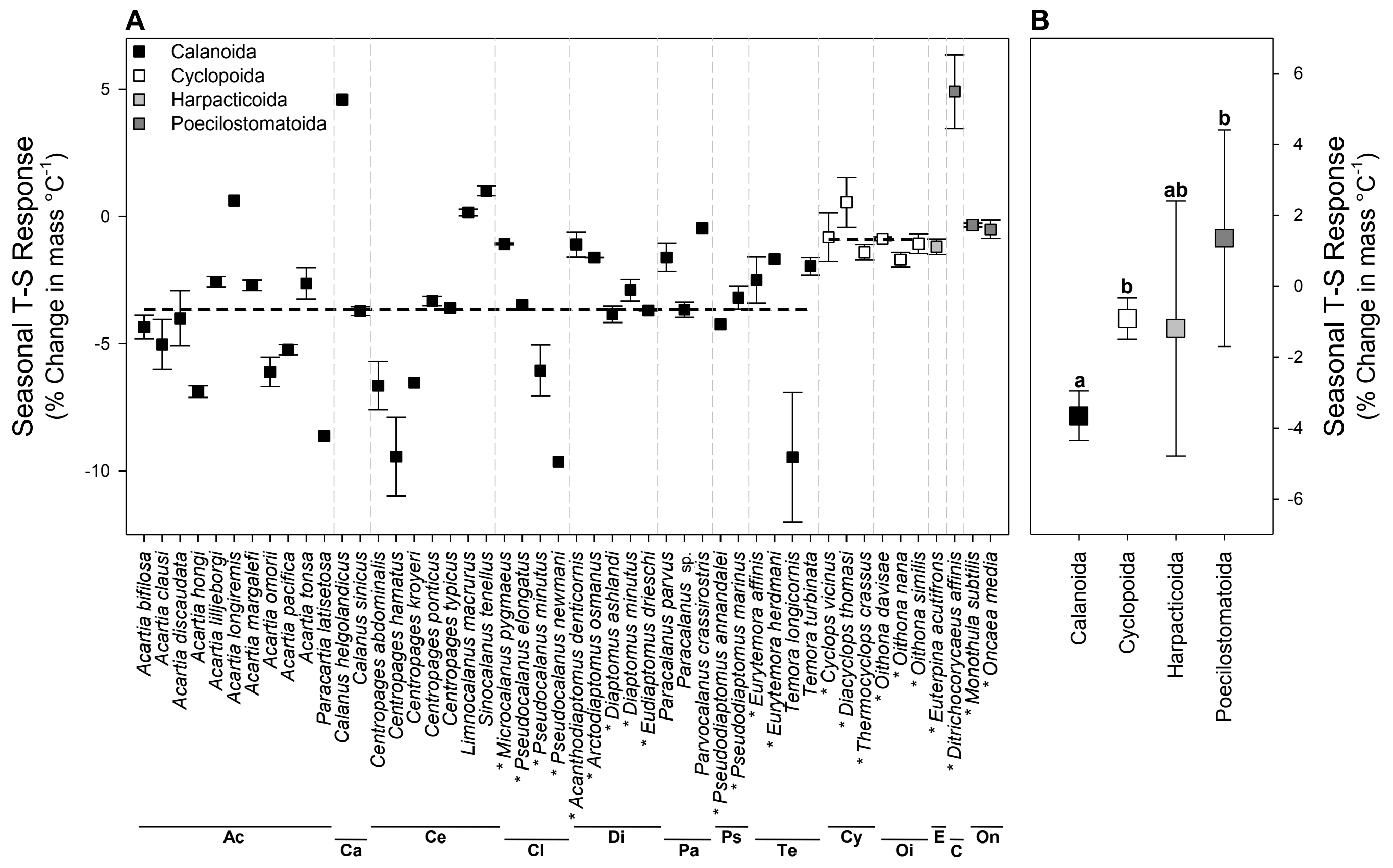




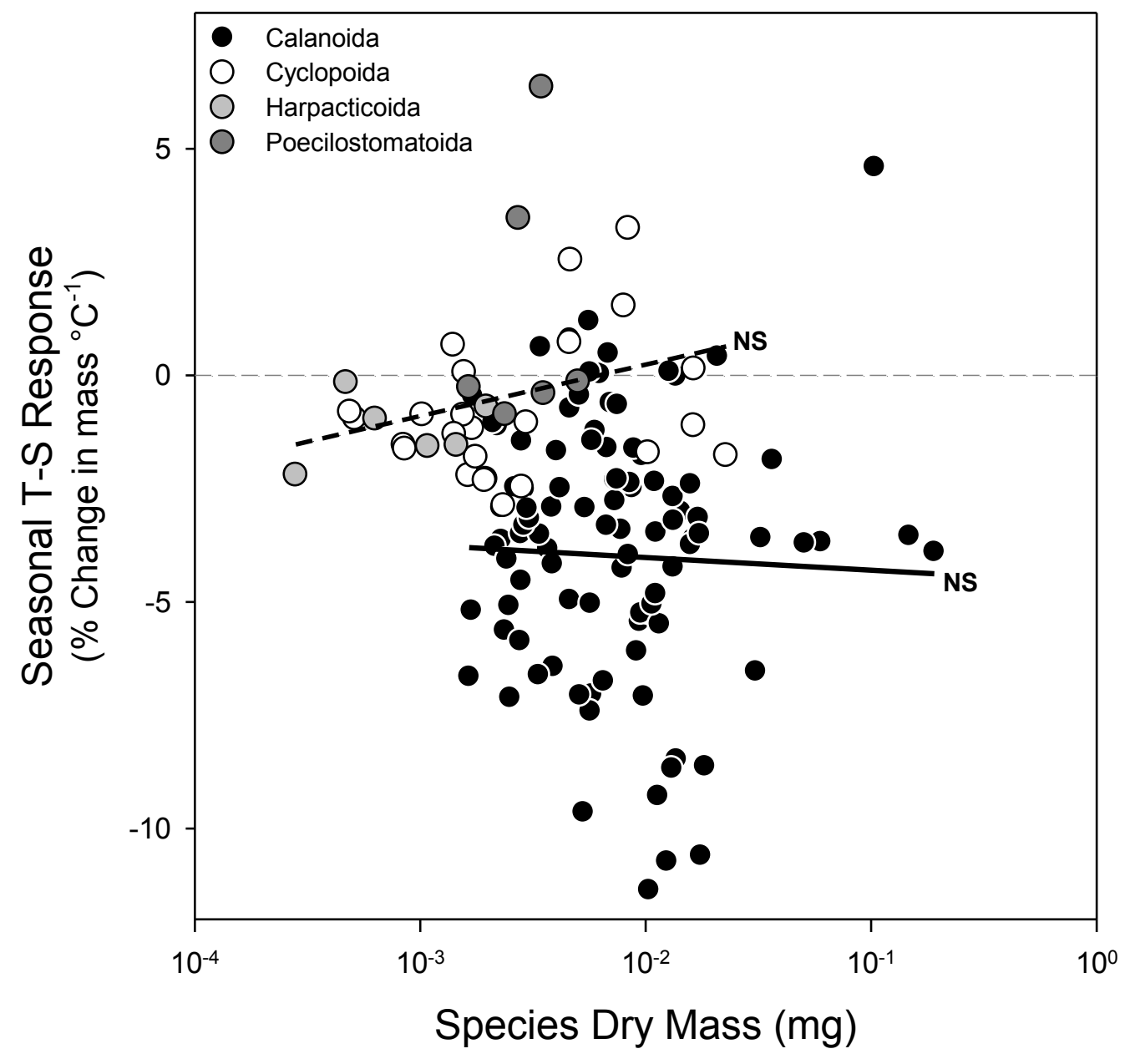

Figure 4 


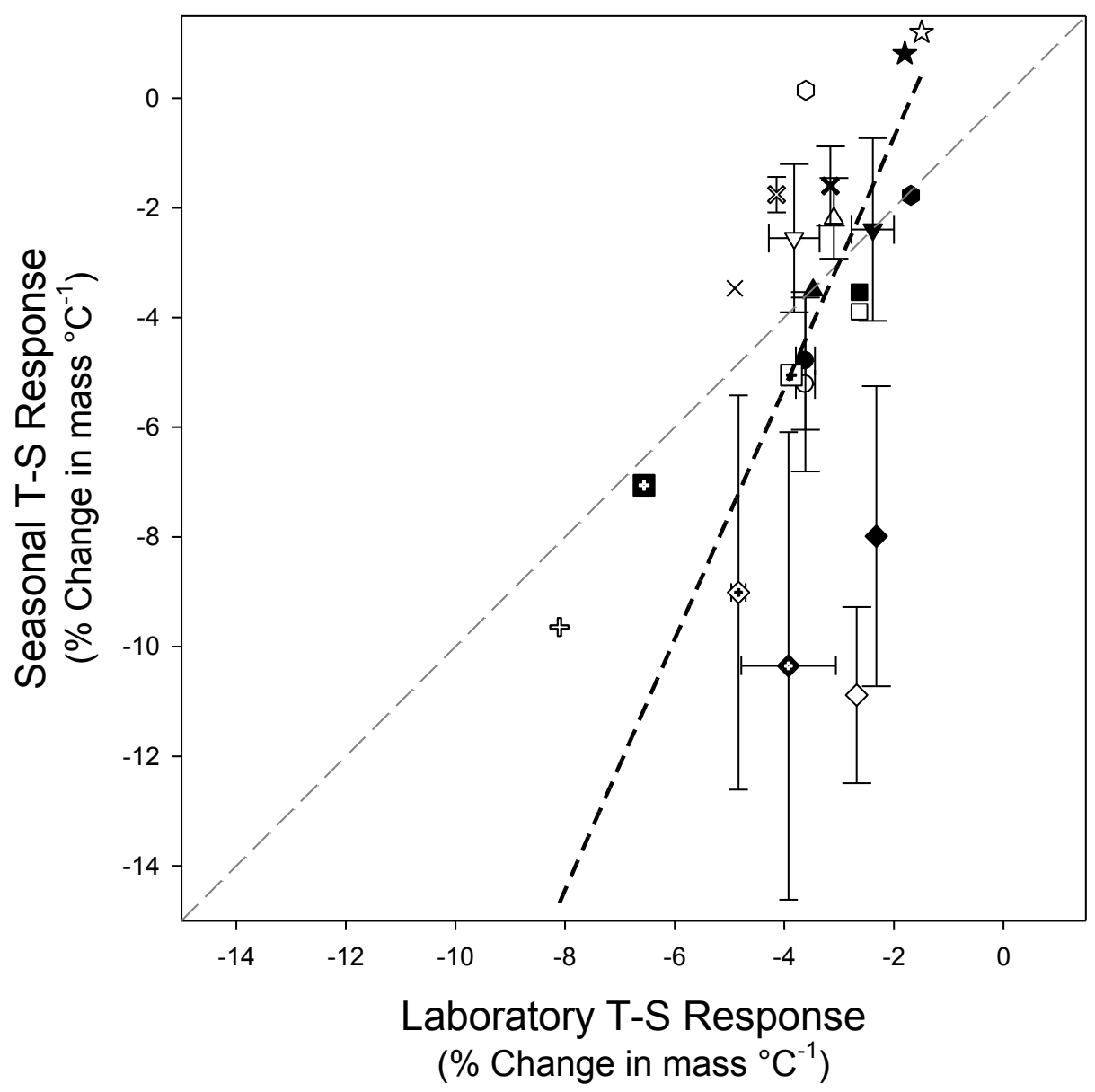

- Acartia clausi F

- Acartia clausi M

$\triangle$ Acartia tonsa $F$

- Acartia tonsa $M$

$\square \quad$ Calanus sinicus $F$

- Calanus sinicus $M$

$\diamond \quad$ Centropages hamatus $F$

- Centropages hamatus M

- Cyclops vicinus $F$

- Cyclops vicinus $M$

$\nabla \quad$ Eurytemora affinis $F$

$\nabla$ Eurytemora affinis $M$

$\times$ Oithona nana $F$

x Oithona nana $M$

$\times \quad$ Pseudocalanus elongatus $F$

$\oplus$ Pseudocalanus minutus $F$

- Pseudocalanus minutus $M$

$\$$ Pseudocalnus newmani $F$

is Sinocalanus tenellus $F$

$\star$ Sinocalanus tenellus $M$

^ Temora longicornis $F$

- Temora longicornis M

Figure 5 